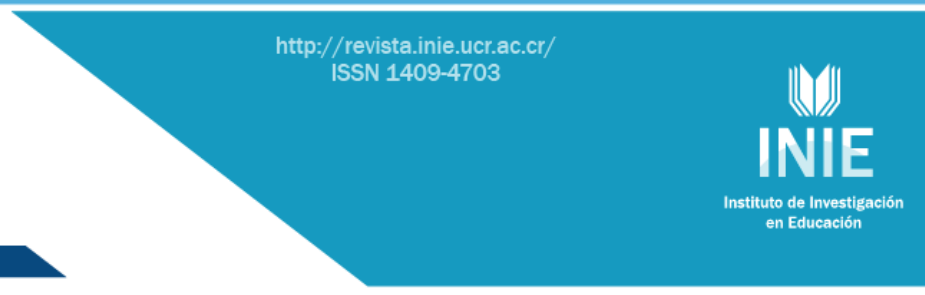

\title{
DESERCIÓN EN ESTUDIANTES DE NUEVO INGRESO A CARRERAS DE DISEÑO. EL CASO DE LA UNIVERSIDAD DE BUENOS AIRES, ARGENTINA \\ DROPOUT BEHAVIOUR OF STUDENTS NEWLY-ENROLLED ON DESIGN COURSES. \\ THE CASE OF THE UNIVERSITY OF BUENOS AIRES, ARGENTINA
}

\author{
Volumen 15, Número 1 \\ Enero - Abril \\ pp. 1-23
}

Este número se publicó el $1^{\circ}$ de enero de 2015

DOI: dx.doi.org/10.15517/aie.v15i1.17735

\author{
Marianela Noriega Biggio \\ Stella Maris Vázquez \\ Stella Maris García
}

Revista indizada en REDALYC, SCIELO

Revista distribuida en las bases de datos:

CATÁLOGO DE LATINDEX, IRESIE, CLASE, DIALNET, DOAJ, E-REVIST@S, SHERPA/ROMEO, QUALIS, MIAR

Revista registrada en los directorios:

ULRICH'S, REDIE, RINACE, OEI, MAESTROTECA, PREAL, CLACSO 


\title{
DESERCIÓN EN ESTUDIANTES DE NUEVO INGRESO A CARRERAS DE DISEÑO. EL CASO DE LA UNIVERSIDAD DE BUENOS AIRES, ARGENTINA

\author{
DROPOUT BEHAVIOUR OF STUDENTS NEWLY-ENROLLED ON DESIGN COURSES.
} THE CASE OF THE UNIVERSITY OF BUENOS AIRES, ARGENTINA
}

\author{
Marianela Noriega Biggio ${ }^{1}$ \\ Stella Maris Vázquez \\ Stella Maris García ${ }^{3}$
}

\begin{abstract}
Resumen: El artículo presenta los resultados de una investigación acerca de los factores que inciden en la deserción y retención en la educación superior. En una muestra de 2273 alumnos del primer año de las carreras de Arquitectura, Diseño y Urbanismo de la Universidad de Buenos Aires, Argentina, que cursaron la materia de Dibujo, se aplicó un instrumento ad-hoc para evaluar la competencia espacial, el cuestionario MSLQ para evaluar los componentes del estilo de aprendizaje y se recogieron los datos demográficos y las calificaciones obtenidas por los alumnos. Se verificó que los factores de más peso en la explicación de la varianza para la deserción/retención fueron el nivel de competencia espacial en el momento de iniciar el curso, el rendimiento del primer semestre y las variables relacionadas con el estilo de aprendizaje. Además, se verificaron relaciones con factores demográficos: sexo, momento de inscripción, lugar de proveniencia y tipo de escuela media, gestión y orientación. De estos resultados surgen algunas reflexiones en el plano pedagógico, referidas a la necesidad de contribuir a que los alumnos desarrollen estilos de aprendizaje adaptativos, que les permitan asumir positivamente las exigencias que se derivan del nuevo ámbito de estudio, en el que es preciso crecer en la autoregulación.
\end{abstract}

Palabras clave: DESERCIÓN, RETENCIÓN, COMPETENCIA ESPACIAL, RENDIMIENTO ACADÉMICO, ESTILOS DE APRENDIZAJE, EDUCACIÓN SUPERIOR, ARGENTINA.

\begin{abstract}
The paper reports a study of the factors behind retention and dropping out phenomena at higher education level. The sample was made up of 2273 fist-year students enrolled on the drawing course at the Architecture, Design, and Urban Planning School, University of Buenos Aires. An ad hoc instrument was devised to assess spatial competence, and the Motivated Strategies for Learning Questionnaire (MSLQ) was used to determine learning style. Demographic data and students marks were also gathered. It was verified that the more significant factors in the explanation of the variance for the attrition/retention were the level of spatial competence in the moment of starting the course, the performance of the first semester and variables related to the learning style. In addition, relationships with demographic factors were verified: sex, time of registration, place of origin and type of middle school, management and orientation. From these results, some reflections arise in the classroom level, based on the need to help students develop styles of adaptive learning, enabling them to positively take on the demands arising from the new field of study, in which it must grow in self-regulation.
\end{abstract}

Key words: DROP-OUT, RETENTION, SPATIAL COMPETENCE, ACADEMIC PERFORMANCE, LEARNING STYLES, HIGHER EDUCATION, ARGENTINA.

\footnotetext{
1 Jefe de Trabajos Prácticos del Ciclo Básico Común en la Facultad de Arquitectura Diseño y Urbanismo de la Universidad de Buenos Aires, Argentina. Arquitecta. Personal de apoyo del Centro de Investigaciones en Antropología Filosófica y Cultural (CIAFIC), Argentina. Dirección electrónica: marianelanoriega@gmail.com

2 Investigadora Independiente (CIAFIC-CONICET), Argentina. Doctora en Filosofía de la Universidad Nacional de Cuyo, Argentina, Profesora de Pedagogía y Bachiller en Teología. Dirección electrónica: stellavazquez@gmail.com

${ }^{3}$ Profesora Titular del Ciclo Básico Común en la Facultad de Arquitectura, Diseño y Urbanismo de la Universidad de Buenos Aires, Argentina. Arquitecta. Especialista en Lógica y Técnica de la Forma.Dirección electrónica: stellagarciacalvo@gmail.com
}

Artículo recibido: 5 de febrero, 2014

Enviado a corrección: 12 de agosto, 2014

Aprobado: 16 de diciembre, 2014 


\section{Introducción ${ }^{4}$}

El fracaso académico y la deserción son dos importantes indicadores de calidad educativa. En la universidad, ambos fenómenos se producen de modo más notable en el primer año de los estudios y se han agudizado en las últimas dos décadas, a partir de la expansión de la matrícula, que se da sobre todo en América Latina, desde los años noventa (Biazus, 2004; Gómez-Senent Martínez y otros, 2004; López-Justicia y otros, 2008, Parrino, 2010).

En Latinoamérica (Informe IESALC, 2006) la matrícula de la educación superior se ha duplicado entre 1996 y 2006, pero es más baja para Chile y Brasil -que, sin embargo, tienen tasas más altas de graduación- y más alta para Argentina, México y República Dominicana.

El período más crítico es el primer semestre, como lo señalan diversas investigaciones. En países europeos, distintos Informes indican que el abandono en el primer año se ubica entre el 16 y $24 \%$ y parece estar asociado con variables de tipo personal, más que contextuales (Cabrera y otros, 2006; Lowis y Castley 2008; Baldwin, 2007; Bethencourt Benítez y otros, 2008).

En nuestro país, en la Universidad de Buenos Aires (UBA), en 1985 se creó el Ciclo Básico Común ( $\mathrm{CBC})$, que constituye el primer año de los estudios universitarios, y cuyos objetivos generales son: "brindar una formación básica, integral e interdisciplinaria; desarrollar el pensamiento crítico; consolidar metodologías de aprendizaje y contribuir a una formación ética, cívica y democrática de los alumnos de la universidad" ${ }^{5}$. El ingreso al CBC es irrestricto y está compuesto por 6 materias: dos comunes a todas las carreras, dos según la orientación en la que está comprendida la carrera elegida y dos específicas de dicha carrera. Además, los estudiantes que seguirán sus estudios en la Facultad de Arquitectura, Diseño y Urbanismo (FADU) ${ }^{6}$ deben cursar un taller anual de Dibujo. La aprobación de estas materias es obligatoria para proseguir los estudios en la carrera elegida.

En la investigación cuyos resultados presentamos, realizada con estudiantes que cursan taller de Dibujo del Ciclo Básico Común (CBC) en la Facultad de Arquitectura, Diseño y Urbanismo (FADU) de la Universidad de Buenos Aires (UBA), nos hemos centrado en

\footnotetext{
4 Esta experiencia se realizó en el marco del proyecto UBACyT 2010-2012/2012-2014 "Competencia espacial para el proyecto del hábitat. Experiencia didáctica en el aprendizaje del dibujo". Equipo de Investigación Directora: Arq. Stella Maris García. Investigadores: Arq. Carlos Barone; Arq. Mariana Basiglio; Arq. Marianela Noriega Biggio; Arq. Laura Oliva; Dra. en Filosofía Stella Maris Vázquez

5 Universidad de Buenos Aires, Ciclo Básico Común. Recuperado de http://www.cbc.uba.ar/Introduccion

6 Las carreras que se dictan en la FADU son: Arquitectura, Diseño Gráfico, Diseño Industrial, Diseño de Indumentaria y Textil, Diseño de Imagen y Sonido, Licenciatura en Planificación y Diseño del Paisaje.
} 
particular, en lo que respecta a factores personales, en el dominio de habilidades que integran la competencia espacial -dado el tipo de carreras que se dictan en la población a la que pertenece nuestra muestra- y en los patrones diferenciales de metas motivacionales y uso de estrategias, que integran el estilo o patrón de aprendizaje, diferenciado para cada uno de los sujetos. Además, se ha intentado relacionar estos dos aspectos con variables demográficas tales como el sexo, la escuela media de proveniencia, el momento en que el alumno formaliza su inscripción al CBC y su fuente de información respecto de las características de la carrera elegida.

\section{Referentes Teóricos}

\subsection{Factores que inciden en la deserción}

Los factores que inciden en la deserción han sido agrupados en dos grandes tipos, por una parte se hallan ciertas condiciones socio-estructurales, entre las cuales se destacan las económicas y las derivadas de los conocimientos y hábitos de estudio que aporta la escuela media, por otra, cada vez se insiste más en factores de tipo personal: metas, motivaciones, nivel de compromiso con la nueva actividad académica, gestión eficaz del tiempo.

Distintos autores señalan que el fracaso en el primer año de universidad se asocia con la concepción del conocimiento que trae el estudiante (Neto Borges y otros, 2003; Tynjälä y otros, 2005), con el predominio de estrategias de estudio superficiales (Rowe, 2002), o la aplicación deficiente de estrategias de estudio (generales o específicas) de los contenidos de cada carrera, con las metas y motivaciones de los alumnos (Silva, 2005), en particular con la capacidad de persistencia y el manejo eficiente del tiempo de estudio. Se destaca la necesidad de que los alumnos adviertan que el estudio en la universidad debe ser cada vez más independiente (Broad, 2006) y debe tener prioridad el aprendizaje conceptual, que crea un potencial para generar nuevos conocimientos, lo que a su vez requiere un modo de enseñar y de evaluar compatible con la aplicación de estrategias de profundidad, más allá de las estrategias básicas que se traen del nivel medio (Washer, 2007).

En la investigación actual estos factores son considerados como componentes del estilo de aprendizaje, término que alude a una forma de estudiar y de considerar la actividad de estudio, relativamente estable, pero no inmutable. El estilo no es visto como un rasgo de personalidad, sino como el resultado de un inter-juego temporal entre aspectos personales y contextuales (Vermunt, 1998; Vermunt y Verloop, 1999), que integra en un todo aspectos motivacionales, conductuales, concepciones de lo que es aprender, uso de estrategias de 
procesamiento cognitivo y de regulación, tanto de procesos como de resultados, cada uno de ellos asociado de un modo característico con los restantes (Vázquez, 2009) y que juega un rol decisivo en la predicción del rendimiento académico (Diseth y Martinsen, 2003; McKenzie, Gow y Schweitzer, 2004; Valadas, Ribeiro Gonçalves y Madeira Faísca, 2010).

Dentro de estos estilos hay un acuerdo en considerar que el estilo de aprendizaje más exitoso, y por tanto el que se debe promover en los alumnos, es el que se caracteriza por la motivación intrínseca, la autorregulación y el uso de estrategias profundas, denominado estilo auto-regulado (Pintrich y Zusho, 2002; Puustinen y Pulkkinnen, 2001) .

Los estudiantes autorregulados dirigen su aprendizaje a través del uso de una serie de estrategias cognitivas, metacognitivas, motivacionales y de apoyo que les permiten regular y controlar de forma intencional todo el proceso -conocen sus habilidades, los conocimientos que poseen, saben qué deben hacer para aprender, han aprendido a monitorear sus conductas de estudio, advierten qué exigencias tienen las tareas que se proponen en el ámbito académico. Por otra parte, son sujetos que tienen motivación para aprender y son capaces de regular esa motivación; tienen iniciativa, son capaces de mantener el esfuerzo, de controlar los factores internos y externos que pueden debilitar el esfuerzo.

El aprendizaje autorregulado exige del alumno la toma de conciencia de las dificultades que pueden impedir el aprendizaje, la utilización deliberada de procedimientos (estrategias) encaminada a alcanzar sus metas, y el control detallado de las variables afectivas y cognitivas. Por otra parte, hay investigaciones que informan sobre las diferencias por sexo en el uso de estrategias, en particular las mujeres aventajan a los varones en las estrategias de organización, manejo de tiempo y de ambiente, regulación del esfuerzo (Ray, Garavalia y Gredler, 2003), planificación y fijación de metas (Pajares, 2002). También se han hallado niveles más altos de motivación intrínseca y valor dado a las tareas académicas en las mujeres (Abar y Loken, 2010; Vrugt y Oort, 2008).

\subsection{La deserción en el contexto nacional en Argentina}

De acuerdo con las estadísticas oficiales correspondientes a 2011, treinta de cada cien habitantes de nuestro país asisten a establecimientos educativos y la población universitaria representa alrededor del $4 \%$ de la población y el 17\% de los estudiantes de todo el sistema.

El sistema universitario en Argentina se caracteriza por una gran heterogeneidad. En 1975 había 24 universidades de gestión estatal y 21 de gestión privada. A partir de 1983, con el advenimiento de la democracia, se desarrolla una tendencia a descentralizar los servicios 
educativos universitarios y al comienzo del $S$ XXI se contaban ya 39 universidades de gestión estatal, varias de las cuales tienen un número variable de filiales en distintas localidades, 6 institutos universitarios estatales, 41 universidades privadas y 12 institutos universitarios privados. En la actualidad hay 47 universidades de gestión estatal, 9 de ellas se crearon en la última década

En particular, dentro del tema del que se ocupa este trabajo, cabe señalar que los modos de acceso a los estudios universitarios varían según el criterio de cada una de las instituciones. De acuerdo con la clasificación de Sigal (Sigal, 2003; Ramallo y Sigal, 2010), estos modos se pueden agrupar en tres tipos, cada uno de los cuales, a su vez, tiene modos de implementación diversificadas:

a) Ingreso irrestricto (puede ser directo, sin otro requisito que el certificado de aprobación del nivel medio o con cursos de apoyo de orientación, no eliminatorios).

b) Ingreso por la aprobación de un examen, sin cupo (con ciclos de nivelación, pruebas de aptitud específicas, etc.).

c) Ingreso por examen, con cupo.

A esto debe agregarse que en la última década muchas universidades han llevado adelante distintas iniciativas de articulación con el Nivel Medio, todas ellas tendientes a aumentar la matrícula, la probabilidad de éxito académico de los futuros alumnos y, en consecuencia, la disminución de la deserción. En la universidad de gestión estatal prevalece la modalidad de ingreso irrestricto.

La Universidad de Buenos Aires queda fuera de esta clasificación, ya que, como se explicó más arriba, ha implementado el Ciclo Básico Común, considerando a los inscriptos en el mismo como estudiantes universitarios.

Según algunos autores (García Guadilla, 1991, Parrino, 2010), en todos los casos hay selección, ya sea explícita o implícita; esta última se evidencia en el desgranamiento que se opera a lo largo del primer año de los estudios universitarios. Así, en Argentina, según datos de $2008^{7}$, el $50 \%$ abandona antes de llegar al segundo año y se consigna un $37,5 \%$ de alumnos reinscriptos, que en el año anterior no habían aprobado ninguna materia o sólo una.

Las tasas de graduación en la Argentina, en la última década, han tenido una evolución que se sintetiza en la Tabla 1:

\footnotetext{
${ }^{7}$ Foro sobre Educación Superior Pública en el Siglo XXI. Recuperado de http://www.elsigloweb.com/nota/15874/el-50-por-ciento-de-los-estudiantes-deja-su-carrera.html
} 
Tabla 1

Tasas de graduación en la Argentina entre 2003 y 2011

\begin{tabular}{|l|c|c|c|c|c|c|c|c|c|}
\hline & $\mathbf{2 0 0 3}$ & $\mathbf{2 0 0 4}$ & $\mathbf{2 0 0 5}$ & $\mathbf{2 0 0 6}$ & $\mathbf{2 0 0 7}$ & $\mathbf{2 0 0 8}$ & $\mathbf{2 0 0 9}$ & $\mathbf{2 0 1 0}$ & $\mathbf{2 0 1 1}$ \\
\cline { 2 - 10 } & $\%$ & $\%$ & $\%$ & $\%$ & $\%$ & $\%$ & $\%$ & $\%$ & $\%$ \\
\hline Estatal & 23,5 & 22,4 & 21,9 & 21,5 & 20,2 & 21,4 & 23,1 & 24,1 & 27,1 \\
\hline Privado & 33,6 & 34,8 & 37,1 & 39,3 & 45,1 & 46,0 & 39,7 & 37,5 & 41,7 \\
\hline Total & 25,4 & 24,6 & 24,6 & 24,4 & 23,9 & 25,7 & 26,3 & 26,9 & 30,6 \\
\hline
\end{tabular}

De la Tabla se desprende que, considerando los porcentajes globales, la tasa se ha mantenido constante, con un leve aumento en 2011. Sin embargo, si se toman en cuenta los valores desagregados, se advierte que esa constante corresponde a las universidades de gestión estatal, mientras que en el caso de las de gestión privada la tasa se ha incrementado de modo significativo en menos de una década.

Los valores de esta tasa permiten aproximarse a los valores de la deserción, ya que si bien esta expresa, de modo directo, el porcentaje de alumnos que se han graduado en el período de duración estipulado teóricamente como duración de las carreras, el hecho de tomar los valores correspondientes a una década permitiría inferir que la tasa de deserción media está por encima del 70\% -y casi alcanza el $80 \%$ para la universidad estatal-, lo que sería congruente con la información de las estadísticas que fijan el abandono del primer año en $50 \%$. En el resto de los años se produciría una deserción de más del $20 \%$.

Por otra parte, en el caso de las universidades estatales se observa una importante dispersión regional, que torna no representativa la media, ya que mientras en universidades del noroeste y sur del país esa tasa se ubica entre el $5 \%$ y $7 \%$, el valor más alto de graduación corresponde a la Universidad de Córdoba -región central-, con 40 graduados cada 100 ingresantes.

La interpretación de esta dispersión excede el marco de los objetivos de este trabajo, pero puede pensarse, por una parte, en las características socio-económico-culturales que diferencian las regiones del país, y, por otra parte, en los perfiles institucionales de las universidades.

En todos los casos estamos siempre lejos de cifras homólogas respecto de otros países, incluso de Brasil, que triplica nuestra tasa de retención y, en consecuencia, de graduación (Guadagni, 2011).

En el caso que nos ocupa, según los informes anuales de la Secretaría de Políticas Universitarias (Argentina, 1999-2011), la tasa de egresos -la razón entre número de 
ingresantes y de egresados por cohorte-, para las carreras que integran la FADU, en 2008 fue del $11 \%$ y en 2010 del 18\%, para el resto de los años no se tienen datos desagregados.

\section{Objetivos}

La investigación se centró en la exploración de:

- La relación entre deserción y niveles de competencia espacial.

- El rol mediador de los estilos de aprendizaje en esa relación.

- La influencia de factores demográficos en la tasa de deserción: sexo, escuela de proveniencia (técnica-no técnica, privada-estatal), fuente de información acerca de la carrera elegida (escuela, orientación vocacional, familia, internet, otras fuentes), atribuciones de habilidad para el dibujo a mano alzada, conocimientos previos de dibujo técnico, lugar de proveniencia de los alumnos (Ciudad de Buenos Aires y Gran Buenos Aires, interior del país o país extranjero), momento en que se efectiviza la inscripción (octubre/noviembre, antes o después), carrera para la que se inscriben en el CBC.

\section{Método}

\subsection{Muestra}

La muestra está integrada por un total de 2273 alumnos que cursan un taller de Dibujo del CBC en la FADU de las cohortes 2010, 2011 y 2012; se compone de un 69\% de mujeres y $31 \%$ de varones, proporción que respeta la composición de la población de la que se toma la muestra. La edad promedio es $\mathrm{X}=18.74 \mathrm{SD}=2.36$. Hay un $6.5 \%$ de alumnos que provienen del extranjero, 16.5\% provenientes del interior del país, el resto de la Ciudad de Buenos Aires y Gran Buenos Aires. Del nivel medio de gestión estatal proviene el $29.4 \%$, el resto hizo sus estudios en escuelas de gestión privada.

\subsection{Diseño}

Se usó un diseño transversal, no probabilístico, no experimental -no se manipularon variables-, de carácter intencional -porque se trabajó con los alumnos que cursaban la materia, sin establecer otro criterio de selección- y ecológico -ya que los datos se recogieron en el aula.

Para el análisis de los datos se usaron los siguientes estadísticos: análisis de varianza (ANOVA one way), prueba $\mathrm{X}^{2}$, pruebas de significación de la diferencia de proporciones, análisis factorial de varianza y análisis de conglomerados de K medias. Se usó el SPSS.17. 


\subsection{Instrumentos}

La competencia espacial se evaluó con una prueba preparada ad hoc, compuesta por 12 ítemes. Los cuatro ítemes de rotación pertenecen al Purdue Spatial Visualizations Test/ Visualizations of Rotations (PSVT/TR) (Bodner y Guay, 1997), un test diseñado para evaluar la habilidad de visualizar la rotación de objetos tridimensionales (ver Figura 1). Los cuatro ítems correspondientes a desarrollo de superficies se tomaron de la sub-escala de relaciones espaciales de la prueba DAT -Differential Aptitudes Test- (Bennett, Seashore y Wesman, 1947) (ver Figura 2). Las tareas de desarrollos de superficies permiten evaluar la habilidad de los sujetos para moverse entre las dimensiones del plano al volumen y viceversa y están vinculadas al desarrollo de la habilidad para imaginar proyecciones y para la configuración mental de volúmenes complejos. Por último, cuatro ítemes de proyecciones se elaboraron a partir de ejercicios que son comunes en las tareas de resolución de problemas en carreras técnicas, porque no existen tests estandarizados referidos a este tipo de tareas de visualización. Se pide a los sujetos que identifiquen en las proyecciones dadas (vistas superior, frontal y lateral), qué superficies se corresponden con la perspectiva y que identifiquen en la perspectiva axonométrica de un objeto las superficies que están representadas en sus proyecciones (ver Figura 3). El instrumento se aplicó en situación de aula, con una duración de 45 minutos. Se recogieron 1813 protocolos.

Figura 1

Ítemes de rotación
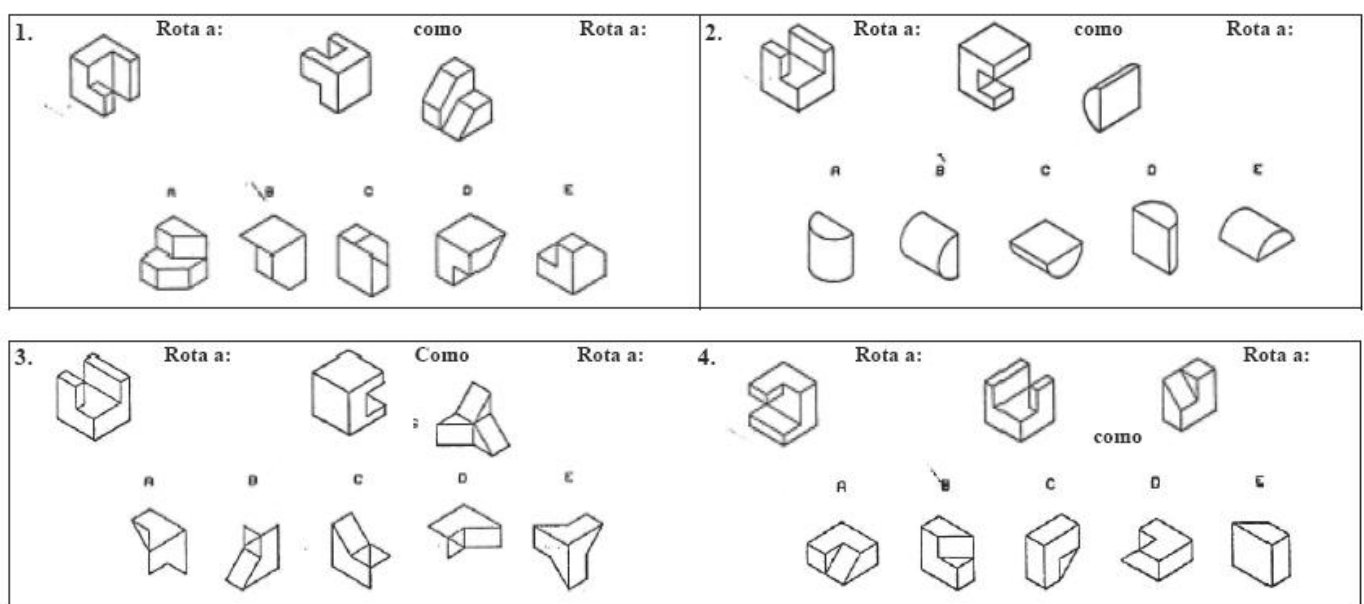

Fuente: Purdue Spatial Visualizations Test/ Visualizations of Rotations (PSVT/TR) (Bodner y Guay, 1997) 
Figura 2

Ítemes de desarrollo

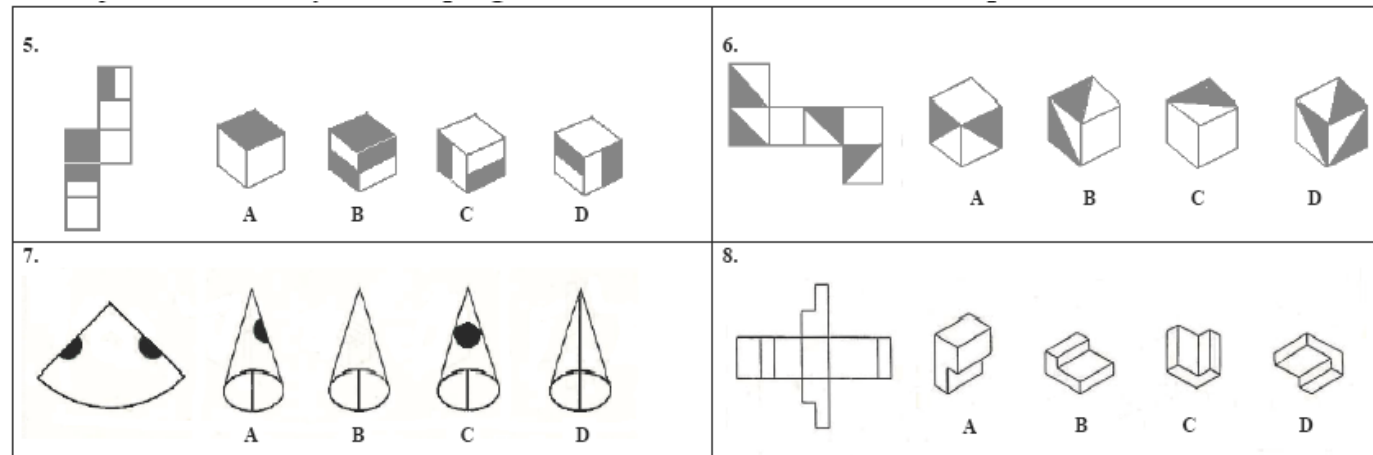

Fuente: Differential Aptitudes Test- (Bennett, Seashore y Wesman, 1947)

Figura 3

Ítemes de proyecciones

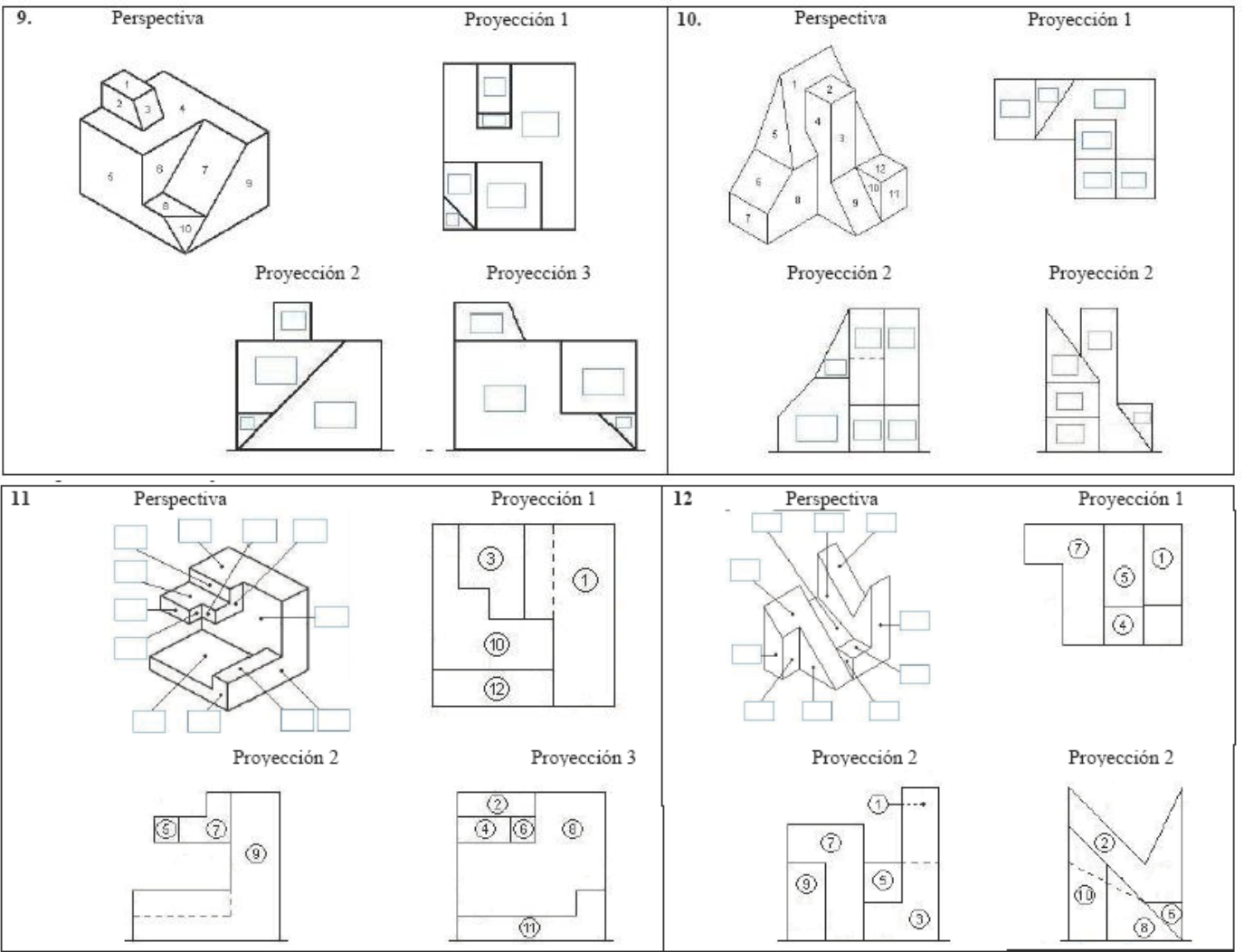

Fuente: Área de Expresión Gráfica en la Ingeniería. Escuela Politécnica Superior. Universidad de Burgos (2010)

En investigaciones previas se probó la validez y confiabilidad de la prueba (Vázquez, García y Noriega Biggio, 2011). 
Para la evaluación de la variable rendimiento académico se recogieron las calificaciones de mitad de año correspondientes a 2273 alumnos. Los valores de la variable están entre 0 y 10.

Para la evaluación de las variables motivacionales y de uso de estrategias -que son los componentes del estilo de aprendizaje- se usó el cuestionario MSLQ (Motivated Strategies for Learning Questionnaire, Pintrich y De Groot, 1990; García Duncan y McKeachie, 2005), un instrumento compuesto por 81 ítems distribuidos en 15 subescalas Lickert que evalúan los componentes cognitivos, metacognitivos y afectivos que forman parte del comportamiento académico autorregulado:

Referidos al aspecto motivacional de expectativas y valor (metas intrínsecas y extrínsecas de la tarea académica; autoeficacia, creencias acerca de la importancia intrínseca de una tarea y de su interés y utilidad para el sujeto; creencias de control de resultados y ansiedad.

Referidos a aspectos cognitivos y socio-cognitivos (Uso de estrategias cognitivas de repetición, elaboración, organización y pensamiento crítico; planificación y monitoreo de la propia actividad; manejo del tiempo y ambiente de estudio; inversión de esfuerzo, inclinación al trabajo en grupo y búsqueda de ayuda).

Para la asignación de puntaje cada ítem del MSLQ se evalúa con una escala Likert (0 a 3), se suma el puntaje obtenido en cada ítem y el resultado se convierte a escala 10. Al finalizar el primer semestre se entregó a cada alumno un cuestionario MSLQ, para su completamiento fuera del horario de clases. Se recogieron 943 protocolos.

\subsection{Procedimiento}

La prueba de competencia espacial se tomó en la primera semana de clase del curso lectivo, dentro del horario de clases y estuvo a cargo de cada uno de los docentes que integran la cátedra de Taller de Dibujo.

El cuestionario MSLQ se entregó a los alumnos antes de finalizar el primer semestre y fue recogido por cada uno de los docentes del Taller.

\section{Resultados}

\subsection{Deserción y rendimiento académico}

El fenómeno de la deserción ocurre, en porcentajes equivalentes antes del cierre del primer semestre (13.7\%) y luego de éste (13.2\%). Si se considera en forma desagregada, en 
2009 y 2010 la deserción fue del 30\%, en 2011 bajó al 20\%, porcentajes que coinciden con los informados para todo el CBC (Ferronato, 2011), y en 2012 creció nuevamente, al 33,4\%.

Un análisis de varianza one way muestra que el rendimiento académico del primer semestre es un factor que pesa de modo decisivo en la retención $[F(1,2271)=287, p<0.01]$ (ver Gráfico 1).

\section{Gráfico 1}

Deserción por Rendimiento académico

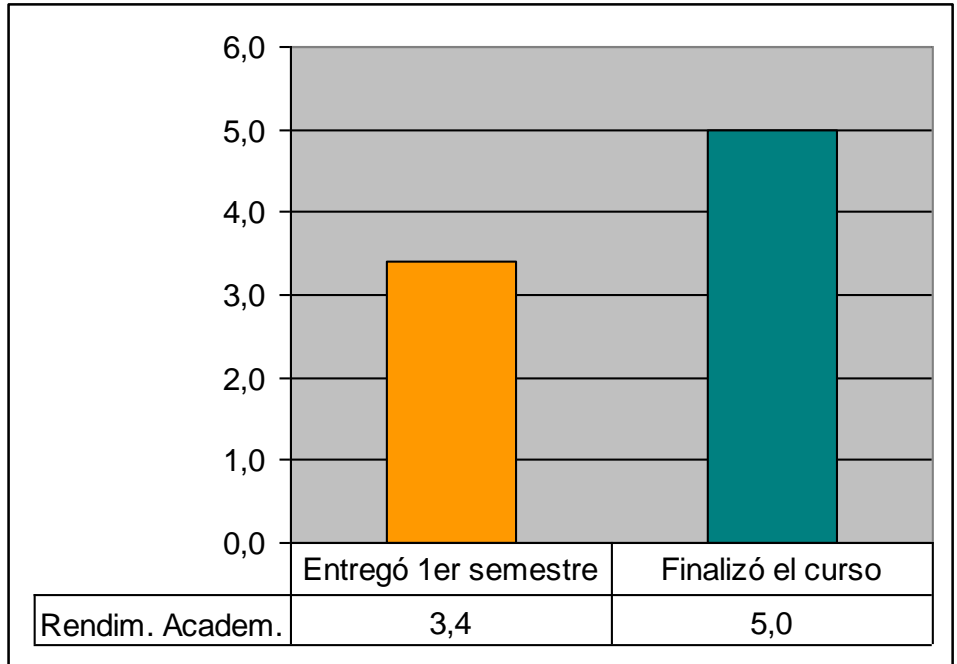

Fuente: Elaboración propia de los autores (2013)

\subsection{Deserción y estilos de aprendizaje}

A partir de los datos recogidos mediante la aplicación del MSLQ se hizo un análisis de conglomerados de $\mathrm{K}$ medias del que surgió la existencia de tres estilos de aprendizaje, que se identificaron como estilo, profundo, intermedio y superficial.

Superficial: Este grupo se caracteriza por el bajo empleo de estrategias cognitivas, muy poca capacidad de autorregulación, de manejo de tiempo y ambiente y de motivación intrínseca.

Intermedio: Es un grupo con un uso moderado de estrategias cognitivas y metacognitivas, con el nivel de ansiedad más alto.

Profundo: Este grupo sobresale por sus metas intrínsecas y el valor que le da a la tarea escolar, informan del uso de estrategias básicas y profundas, manejan su tiempo, ambiente y esfuerzo y buscan ayuda. Tienen un perfil que responde a los rasgos del alumno auto-regulado. 
Para evaluar la relación del estilo de aprendizaje con la deserción, se hace una prueba $\mathrm{X}^{2}$, ya que las variables son categóricas. Con los porcentajes obtenidos se establece la significación de la diferencia de proporciones, lo que permite establecer que el menor porcentaje $\left[X^{2}=8.56\right.$ (2) $\left.p<0.02\right]$ de deserción se da en el grupo de estilo profundo respecto de los otros dos grupos. Por otra parte en la tasa de retención hay diferencia significativa $\left[X^{2}=6.42(2), p<0.02\right]$ entre el grupo de estilo profundo y el de estilo superficial, en favor de los primeros, mientras que no hay diferencia significativa entre deserción y retención en el grupo intermedio. (Ver Gráfico 2).

En efecto, en el gráfico se observa que de la totalidad de los alumnos que desertan sólo un $24 \%$ de los alumnos pertenece al grupo de estilo profundo, en tanto que el $37 \%$ de los que son retenidos en el sistema pertenece a este grupo y sólo un $29 \%$ pertenece al grupo de estilo superficial.

\section{Gráfico 2}

Relación entre Deserción/Retención y Estilos de aprendizaje

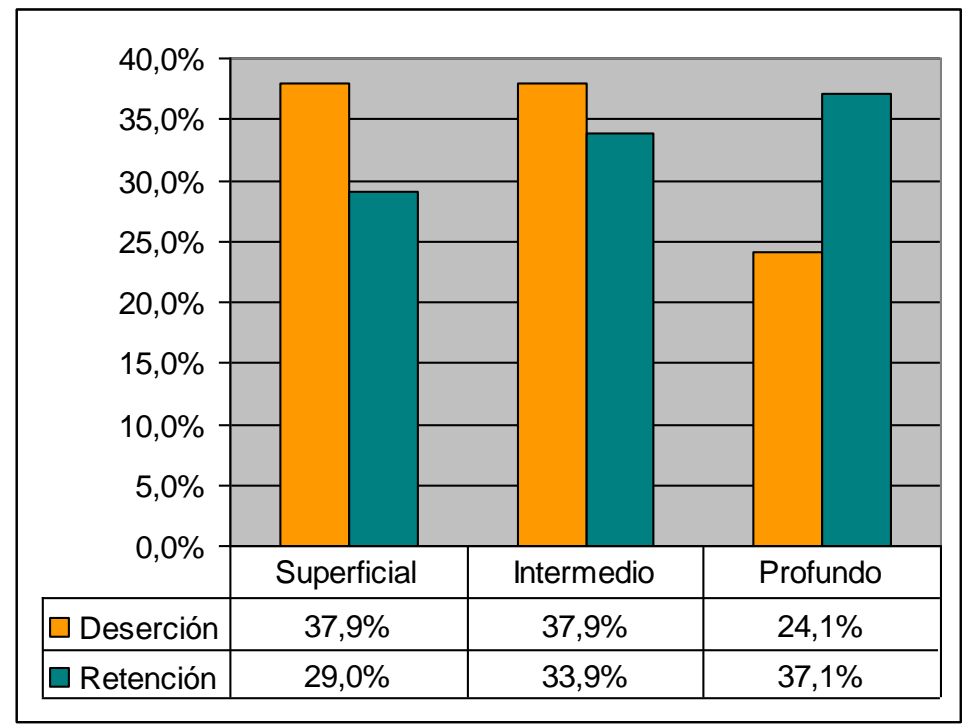

Fuente: Elaboración propia de los autores (2013)

\subsection{Deserción y competencia espacial}

Un análisis de varianza one way permite mostrar que la competencia espacial inicial afecta significativamente el nivel de deserción $[F(1,1812)=42.51, p<0.01]$.

Los que abandonaron tienen una media de competencia espacial cercana a 5.55; a diferencia del grupo de los que finalizan la materia, donde la media es de 6.35 puntos. 
La prueba $\mathrm{X}^{2}$ muestra una relación significativa entre el porcentaje de deserción y los niveles de competencia espacial [ $X^{2}(2)=30.66, p<0.001$ ] (ver Gráfico 3): del grupo de sujetos que desertó, el $48 \%$ tenía bajo nivel de competencia espacial, en tanto que sólo un $22 \%$ tiene alto nivel de competencia espacial.

Gráfico 3

Porcentaje de deserción/retención por niveles de competencia espacial

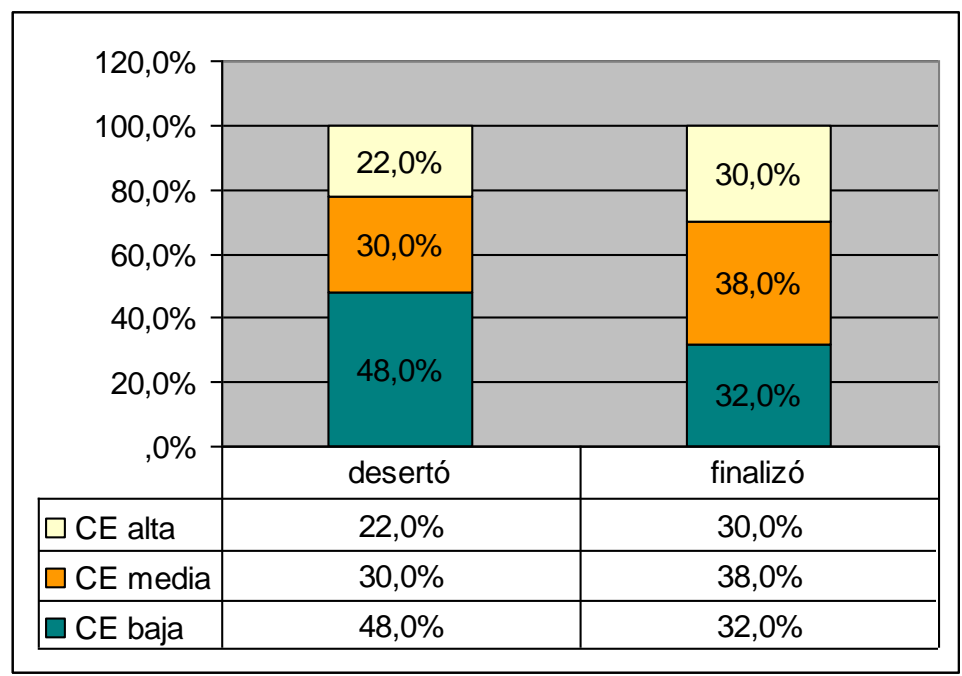

Fuente: Elaboración propia de los autores (2013)

Por otra parte, la prueba de significación de la diferencia de proporciones indica que el grupo de competencia espacial baja se integra con sujetos que en porcentaje significativamente más alto son de estilo intermedio [z=3.59 $p<0.01]$. En el grupo de competencia espacial media no hay diferencias por estilo de aprendizaje y en el grupo de competencia espacial alta hay un porcentaje significativamente menor de sujetos con estilo de aprendizaje intermedio $[z=3.96 p<0.01]$ (ver Tabla 2 ).

Tabla 2

Estilos de aprendizaje por Competencia espacial

\begin{tabular}{|l|l|l|l|l|}
\hline \multicolumn{2}{|c|}{} & \multicolumn{3}{|l|}{ Nivel Compencia espacial } \\
\cline { 3 - 6 } \multicolumn{2}{|c|}{} & BAJO & MEDIO & ALTO \\
\cline { 3 - 5 } \multicolumn{2}{c|}{} & $\%$ & $\%$ & $\%$ \\
\hline \multirow{2}{*}{$\begin{array}{l}\text { Estilos } \\
\text { aprendizaje }\end{array}$} & de & $29.5 \%$ & $31.1 \%$ & 32.6 \\
\cline { 2 - 5 } & Intermedio & $41 \%$ & $31.4 \%$ & $24.4 \%$ \\
\cline { 2 - 5 } & Profundo & $29.5 \%$ & $37.5 \%$ & $43 \%$ \\
\hline
\end{tabular}

Fuente: Elaboración propia de los autores (2013) 
Una lectura alternativa de los mismos datos, informa que ni en el grupo de estilo superficial ni en el grupo de estilo profundo hay diferencias significativas por nivel de competencia espacial, en cambio en el grupo de estilo intermedio si las hay, puesto que en este grupo el $44.9 \%$ tiene un bajo nivel de competencia espacial y sólo el $19.9 \%$ tiene alta competencia espacial $[z=6.02 p<0.01]$ (Ver Gráfico 4).

\section{Gráfico 4}

Nivel de Competencia espacial por estilos de aprendizaje

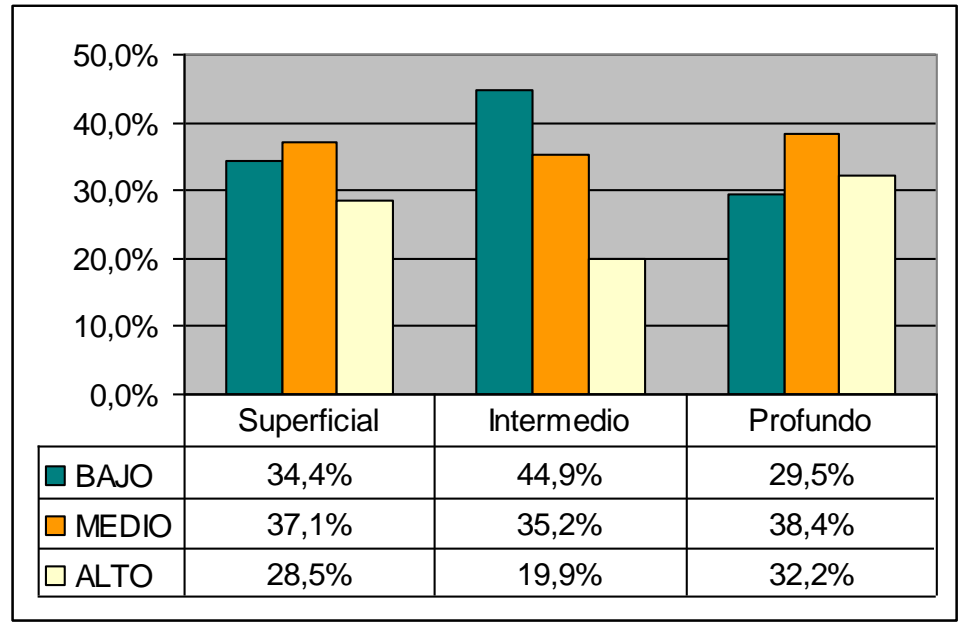

Fuente: Elaboración propia de los autores (2013)

\subsection{Rendimiento académico, competencia espacial y estilos de aprendizaje}

Como se mostró más arriba, el rendimiento del primer semestre es el factor que más incide en el abandono; de allí que sea pertinente preguntarnos en qué medida inciden sobre ese rendimiento parcial los factores antedichos. Un análisis de varianza factorial (Ver Gráfico 5) muestra que el rendimiento más alto corresponde a los alumnos que tienen un estilo de aprendizaje profundo y alta competencia espacial $[F(8,708)=14.78, p<0.001]$. El análisis de varianza one way permite verificar que ambos factores pesan, pero en el caso del grupo con estilo superficial, las diferencias en rendimiento, según niveles de competencia espacial, no son significativas, lo que equivale a decir que en este grupo el estilo implica un lastre negativo, que impide hacer rendir el potencial intelectual. En cambio, sí hay diferencias significativas para los otros dos grupos -estilo intermedio: $F(2)=23.36, p<0.001$; estilo profundo: $F(2)=15.51, p<0.001$ - y en este caso el estilo potencia la capacidad.

Se verifica una interacción $[F(2)=2.65, p<0.04]$ porque el grupo de estilo intermedio y competencia espacial más baja tienen un rendimiento inferior a los del grupo de estilo 
superficial, relación que se invierte para el grupo de estilo intermedio con competencia espacial media o alta.

Gráfico 5

Rendimiento académico, competencia espacial y estilos de aprendizaje

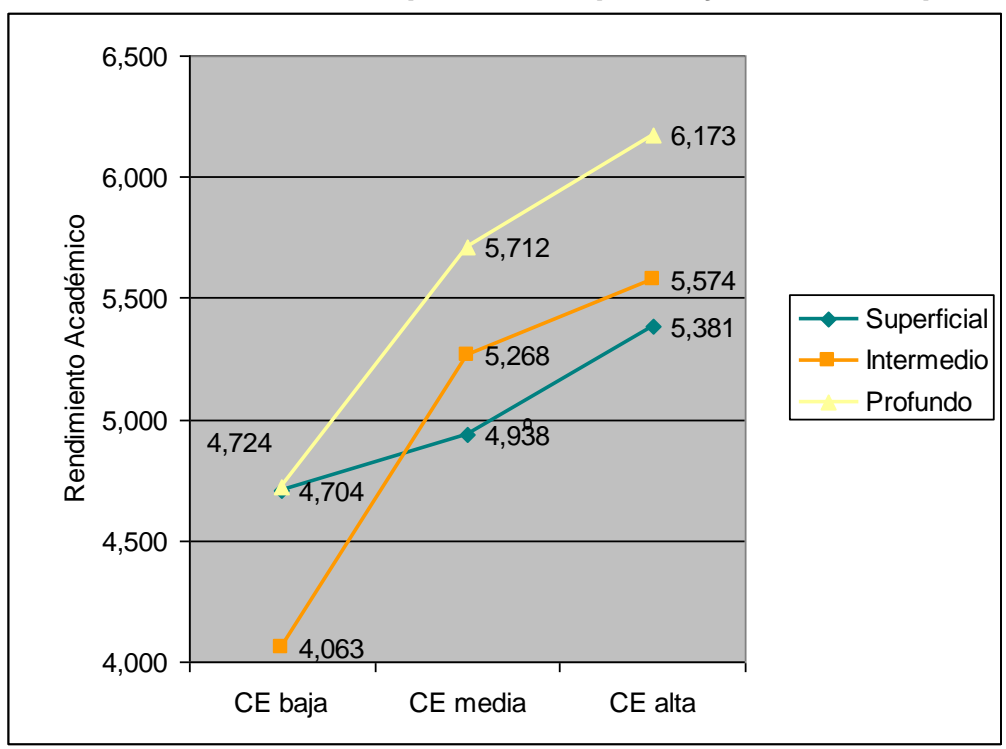

Fuente: Elaboración propia de los autores (2013)

\subsection{Deserción y factores demográficos}

Hay diferencias significativas por sexo $\left[X^{2}(1,2637)=13.97, p<0.001\right]$ (Ver Gráfico 6), ya que el porcentaje de varones que desertan es mayor que el de las mujeres. Tienen tasa más baja de deserción los alumnos que provienen de escuela técnica $\left[X^{2}(1)=3.18, p<\right.$ 0.05] (Ver Gráfico 7), los que han cursado la escuela secundaria en instituciones de gestión privada $\left[X^{2}(1)=25.38 p<0.001\right]$ (Ver Gráfico 8), los alumnos que se inscribieron antes del último llamado $\left[X^{2}(2)=14.28, p<0.002\right]$ (Ver Gráfico 9), los que no se atribuyen baja habilidad en dibujo a mano alzada $\left[X^{2}(3)=15.28 p<0.003\right]$ (Ver Gráfico 10). Los alumnos que se han inscripto en las carreras de Diseño de imagen y sonido y Diseño de indumentaria son los que tienen mayor tasa de deserción $\left[X^{2}(6)=78.05 p<0.001\right]$, en tanto que la mayor tasa de retención la tienen los inscriptos en Arquitectura y Diseño Industrial (Ver Gráfico 11). También se observó menor tasa de deserción en los alumnos que refieren haber recibido información de la carrera en su familia, aunque la diferencia no llega a ser significativa. Por último, hay más deserción en los alumnos que provienen del extranjero $\left[X^{2}(2)=7.31, p<\right.$ 0.03], a diferencia de los que provienen de Ciudad de Buenos Aires y Gran Buenos Aires. 


\section{Gráfico 6}

Deserción por sexos

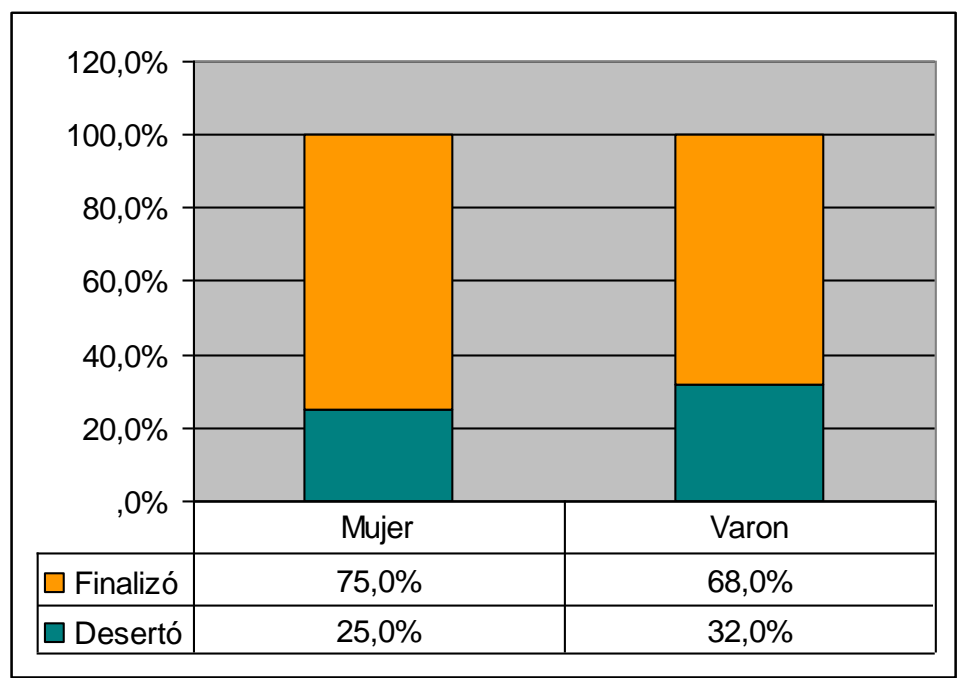

Fuente: Elaboración propia de los autores (2013)

Gráfico 7

Deserción por egreso

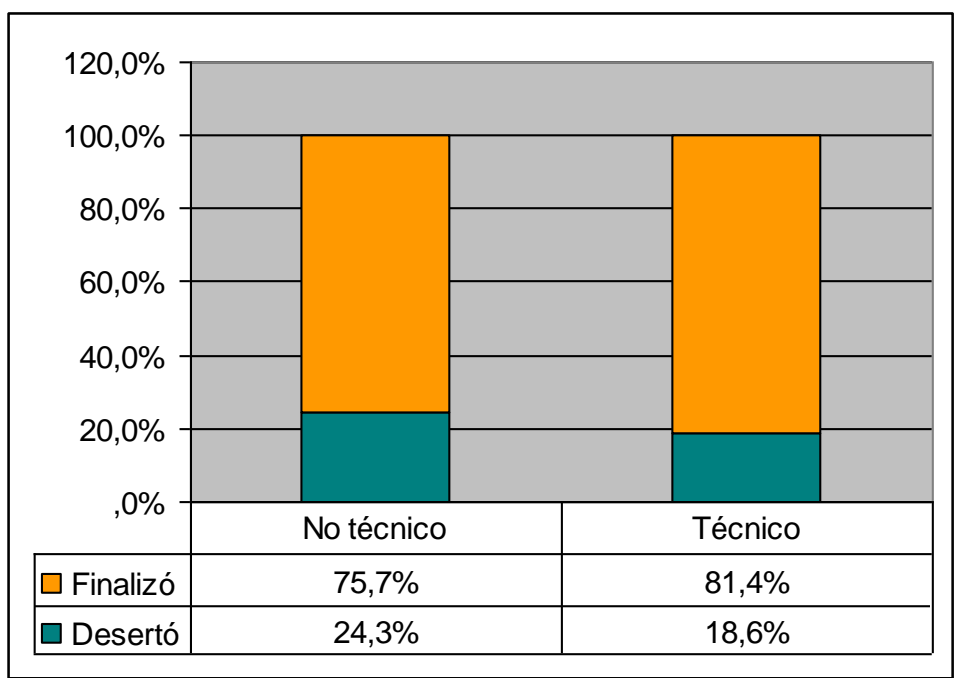

Fuente: Elaboración propia de los autores (2013) 


\section{Gráfico 8}

Deserción por gestión

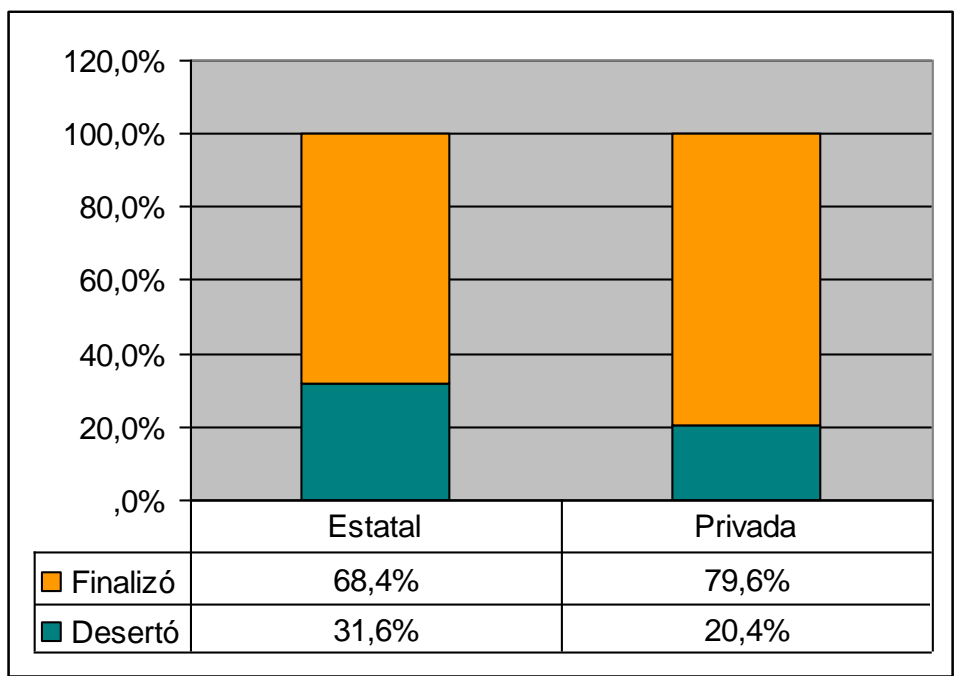

Fuente: Elaboración propia de los autores (2013)

\section{Gráfico 9 \\ Deserción por llamado a inscripción}

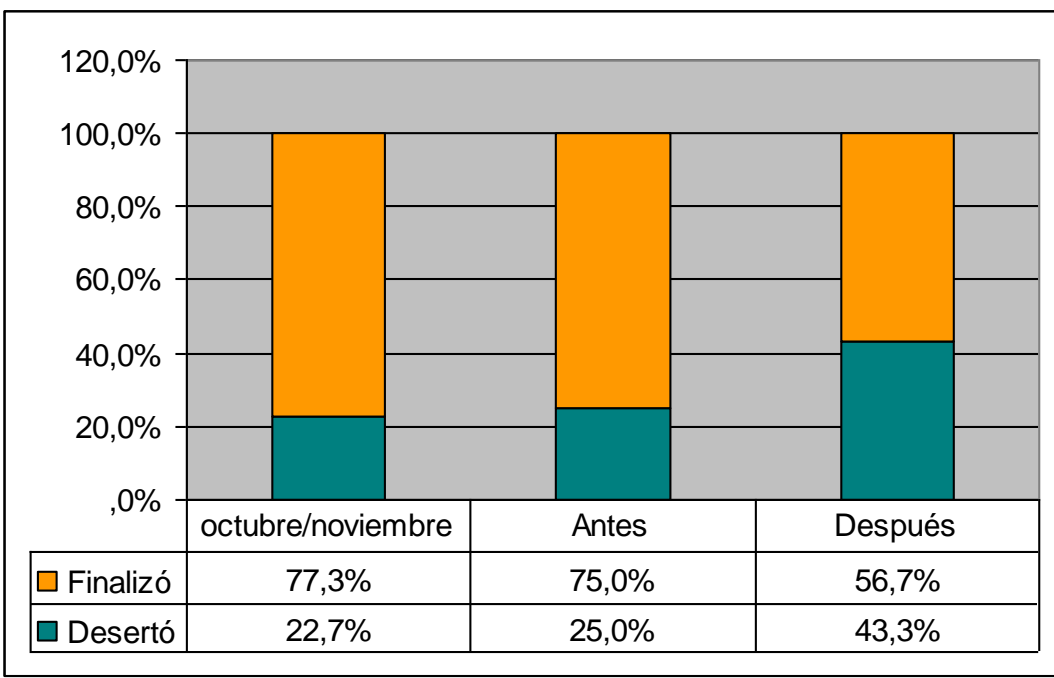

Fuente: Elaboración propia de los autores (2013) 
Gráfico 10

Deserción por atribución en dibujo a mano alzada

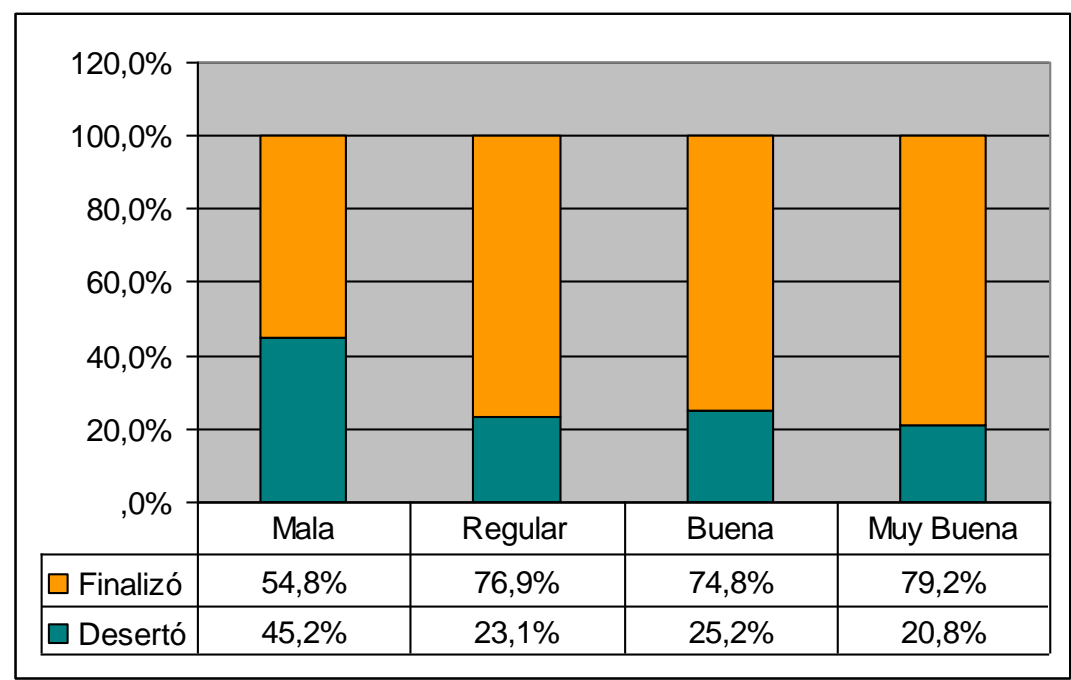

Fuente: Elaboración propia de los autores (2013)

Gráfico 11

Deserción por carrera

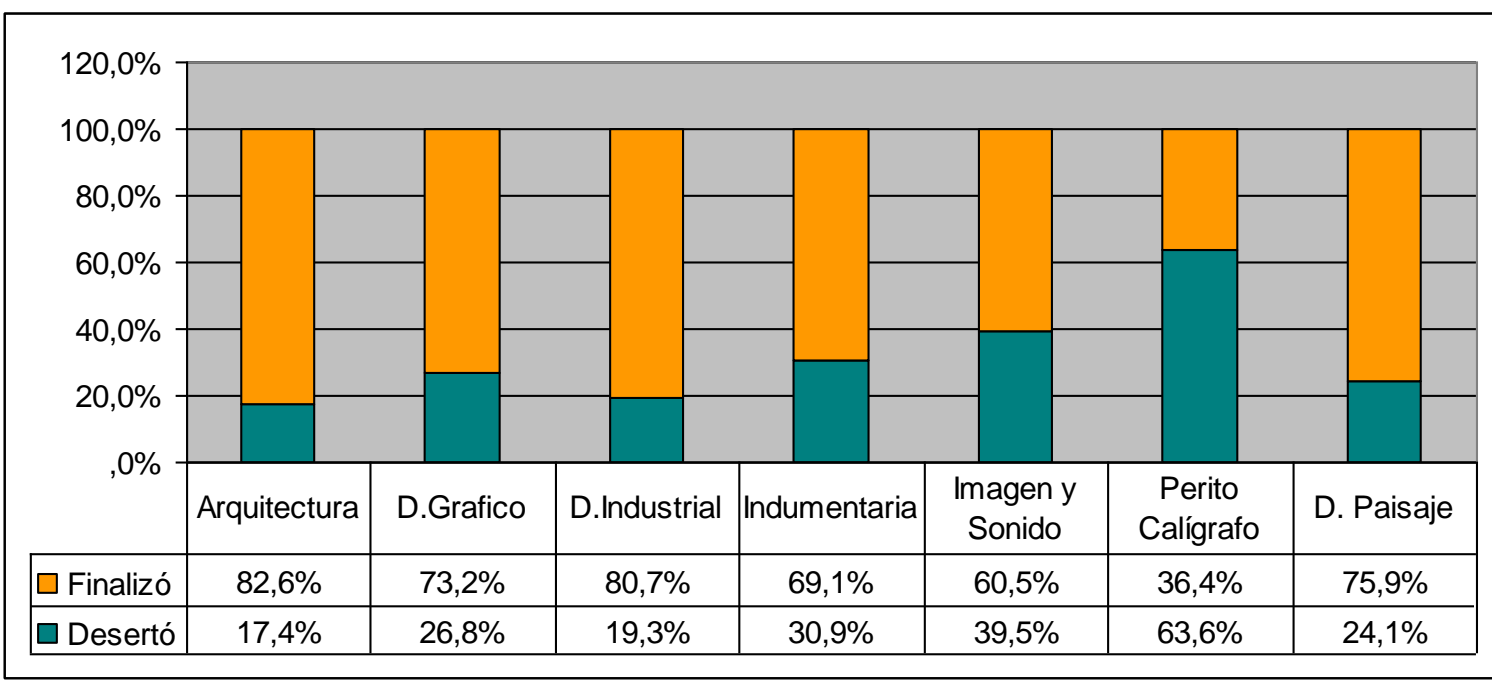

Fuente: Elaboración propia de los autores (2013)

\section{Conclusiones}

A partir del análisis de los datos recogidos se verificó que los factores de más peso en la explicación de la varianza para la deserción/retención fueron el nivel de competencia espacial en el momento de iniciar el curso, el rendimiento del primer semestre y las variables relacionadas con el estilo de aprendizaje. Además, se verificaron relaciones con factores 
demográficos: sexo, momento de inscripción, lugar de proveniencia y tipo de escuela media -gestión y orientación.

El peso de la competencia espacial es relevante -entre los alumnos que desertan, el $48 \%$ tiene un nivel bajo de competencia espacial, y sólo un $22 \%$ tiene alto nivel-, lo que podría inducir a interpretar que permanecen sólo los más capaces; sin embargo, esta interpretación deber ser matizada por la interacción de esta capacidad con otros factores, en primer lugar con el estilo de aprendizaje. En efecto, se mostró que el grupo de desertores contiene un $38 \%$ de sujetos con estilo superficial y sólo un $24 \%$ de sujetos con estilo profundo; lo que permite inferir que cuando los alumnos tienen mayor valoración de la tarea y motivación intrínseca, aplican estrategias de organización, gestionan de modo más eficiente su tiempo de estudio e invierten más esfuerzo en la tarea académica, potencian su capacidad intelectual y, cuando ésta es baja o media, compensan ese déficit y logran finalizar el curso. Los alumnos con estilo profundo alcanzan un rendimiento satisfactorio en el primer semestre, lo que los pone en condiciones más favorables para finalizar el curso. En cambio, los alumnos con estilo superficial no logran potenciar su capacidad, porque no hay diferencias en rendimiento para este grupo en relación con su nivel diferencial de competencia espacial.

Por otra parte, la interacción verificada puede interpretarse en el sentido de que cuando la competencia espacial es muy baja, el estilo no logra superar ese obstáculo, pero con una competencia espacial media o alta el grupo de estilo intermedio supera a los de estilo superficial.

Se verificó también que el porcentaje de mujeres que desertan es menor que el de los varones, lo que podría relacionarse con el peso del estilo de aprendizaje, ya que en investigaciones previas, tanto propias (Vázquez y Noriega Biggio, 2010, Vázquez, Noriega Biggio y García, 2013), como de otros autores (Ray, Garavalia y Gredler, 2003; Pajares, 2002; Abar y Loken, 2010; Vrugt y Oort, 2008) se ha mostrado que las mujeres aventajan a los varones en el empleo de estrategias de profundidad, en valoración de la tarea y en uso del tiempo y solicitud de ayuda, que son componentes centrales del estilo profundo, aunque tienen menor nivel de competencia espacial (Hirnstein, Bayer y Hausmann, 2009; Linn y Petersen, 1985; Voyer, Voyer y Bryden, 1995; Heil y Jansen-Osmann, 2008; Quinn y Liben, 2008).

La diferencia en tasa de deserción, menor para los alumnos que provienen de escuelas de gestión privada, es congruente con datos relevados por otras investigaciones (Guadagni, 
2011). Esto se une al dato de que, según el Censo universitario de 2004, en la Universidad de Buenos Aires el $56 \%$ de los alumnos inscriptos y el $70 \%$ de los graduados provienen de escuelas privadas.

El hecho de que deserten en menor proporción los alumnos que se inscriben antes del último llamado, puede interpretarse en relación con la calidad de la toma de decisión.

Por último, la menor deserción de los alumnos que han recibido información de la carrera por vía familiar, podría deberse a que en estos casos la elección de carrera está sostenida en un contexto profesional afín.

La mayor deserción de alumnos inscriptos para la Carrera de Diseño de Indumentaria contrasta con el hecho de que en 2012 se triplicó la matrícula para esta carrera.

De estos resultados surgen algunas reflexiones en el plano pedagógico, referidas a la necesidad de contribuir a que los alumnos desarrollen estilos de aprendizaje adaptativos, que les permitan asumir positivamente las exigencias que se derivan del nuevo ámbito de estudio, en el que es preciso crecer en la auto-regulación. Más allá de este aspecto, ligado a la dimensión personal, están las reflexiones sobre el rol del contexto social, que deben ser objeto de otro trabajo.

\section{Referencias}

Abar, Beau y Loken, Eric. (2010). Self-regulated learning and self-directed learning in a precollege sample. Learning and Individuals Differences, 20, 25-29.

Argentina, Secretaría de Políticas Universitarias (SPU) del Ministerio de Educación de la Nación. (1999 a 2011). Anuarios de estadísticas universitarias 1999-2011. Buenos Aires. Recuperado de http://portales.educacion.gov.ar/spu/investigacion-yestadisticas/anuarios/

Baldwin, Lynne. (2007). Editorial. Active Learning in Higher Education 8(3), 195-200

Bennet, George, Seashore, Harold y Wesman, Alexander. (1947). Differential Aptitude Test. New York: Psychological Corp.

Bethencourt Benítez, José Tomás, Cabrera Pérez, Lidia, Hernández Cabrera, Juan Andrés, Álvarez Pérez, Pedro y González Afonso, Miriam. (2008). Variables psicológicas y educativas en el abandono universitario. Electronic Journal of Research in Educational Psychology 6(16), 603-622. Recuperado de http://www.investigacionpsicopedagogica.org/revista/new/ContadorArticulo.php?223

Biazus, Cleber Augusto. (2004). Sistema de fatores que influenciam o aluno a evadirse dos cursos de graduação na UFSM. Tese. Universidade Federal de Santa Catarina. Florianópolis, Brasil. 
Bodner, George y Guay, Roland. (1997). The Purdue Visualization of Rotations Test. The Chemical Educator, 2(4), 1-17.

Broad, James. (2006). Interpretations of independent learning in further education. Journal of Further \& Higher Education, 30(2), 119-143.

Cabrera, Lidia, Bethencourt, José Tomás, Álvarez Pérez, Pedro y Gonzalez Afonso, Miriam (2006). El problema del abandono de los estudios universitarios. Relieve 12(2), 171203. Recuperado de http://www.uv.es/relieve/v12n2/RELIEVEv12n2 1.htm

Diseth, Åge y Martinsen, Øyvind. (2003). Approaches to learning, cognitive styles, and motives as predictors of academic achievement. Educational Psychology, 23, 195-207.

Ferronato, Jorge. (2011). El 78\% de los alumnos finaliza el ciclo y arquitectura lidera la inscripción. Noticias Universia, 30 de octubre de 2011: Recuperado de http://noticias.universia.com.ar/vida-universitaria/noticia/2011/10/31/884045/78alumnos-finaliza-ciclo-arquitectura-lidera-inscripcion.html

García Guadilla, Carmen. (1991). Modelos de acceso y politicas de ingreso a la educacion superior. El caso de America Latina y el Caribe. Revista Educación Superior y Sociedad, 2(2), 72-93.

García Duncan, Teresa y McKeachie, Wilbert. (2005). The making of the motivated strategies for learning questionnaire. Educational Psychologist, 40(2), 117-128.

Gómez-Senent Martínez, Eliseo; Carda Batalla, Isabel y Cañizares Domenech, Ana. (2004). Europa Project: education for learning. European Journal of Engineering Education, 29(2), 299-306.

Guadagni, Alieto. (2011). Deserción, Desigualdad y Calidad Educativa. Econométrica S.A economic research and forecasts Informe Especial, (415), 1-18.

Heil, Martin y Jansen-Osmann, Petra. (2008). Sex differences in mental rotation with polygons of different complexity: Do men utilize holistic processes whereas women prefer piecemeal ones? Quarterly Journal of Experimental Psychology, 61(5), 683-689.

Hirnstein, Marco, Bayer, Ulrike y Hausmann, Markus. (2009). Sex-specific response strategies in mental rotation. Learning and Individual Differences, 19(2) 225-228.

Instituto Internacional de la UNESCO para la Educación Superior en América Latina y el Caribe (IESALC). (2006). Informe sobre la educación superior en América Latina y el Caribe. 2000-2005. La metamorfosis de la educación superior. Caracas: UNESCO.

Linn, Marcia y Petersen, Anne. (1985). Emergence and Characterization of Sex Differences in Spatial Ability: A Meta-Analysis. Child Development, 56(6), 1479-1498.

López-Justicia, Ma. Dolores, Hernández, Carmen, Fernández Jiménez, Carolina, Polo Sanchez, Tamara y Chacón López, Elena. (2008). Características formativas y socioafectivas del alumnado de nuevo ingreso en la Universidad. Revista Electrónica de Investigación Psico-educativa, 14(6), 95-115. 
Lowis, Mike y Castley, Andrew. (2008). Factors affecting student progression and achievement: prediction and intervention. A two-year study. Innovations in Education and Teaching International, 45(4), 333-343

McKenzie, Kirsten, Gow, Kathryn y Schweitzer, Robert. (2004). Exploring the first year academic achievement through structural equation modelling. Higher Education Research and Development, 23(1), 95-112.

Neto Borges, Mario, Do Carmo Narciso Silva Gonçalves, Maria y Macedo Cunha, Flavio. (2003). Teaching and learning conceptions in engineering education. European Journal of Engineering Education, 28(4), 523-535.

Pajares, Frank. (2002). Gender and perceived self-efficacy in self-regulated learning. Theory into Practice, 41(2), 116-125.

Parrino, María del Carmen. (2010). Deserción en el primer año universitario. Dificultades y logros. X Coloquio Internacional sobre Gestión Universitaria en América del Sur. Mar del Plata, 8, 9 y 10 de diciembre de 2010.

Pintrich, Paul y Zusho, Akane. (2002). The development of academic self-regulation: The role of cognitive and motivational factors. En A. Wigfield y J.S. Eccles (Eds.), Development of achievement motivation (pp. 249-284). San Diego, CA: Academic Press.

Pintrich, Paul y De Groot, Elizabeth. (1990). Motivated and self-regulated learning components of classroom academic performance. Journal of Educational Psychology, 82(1), 33-40.

Puustinen, Minna y Pulkkinen, Lea. (2001). Models of Self-regulated Learning: a review. Scandinavian Journal of Educational Research, 45(3), 269-286.

Quinn, Paul y Liben, Lynn. (2008). A Sex difference in mental rotation in young infants. Psychological Science, 19(11), 1067-1070.

Ramallo, Milena y Sigal, Víctor (2010). Los sistemas de admisión de las universidades en la Argentina (Documento de Trabajo $\mathrm{N}^{\circ}$ 255). Universidad de Belgrano. Recuperado de http://www.ub.edu.ar/investigaciones/dt nuevos/255 Sigal.pdf

Ray, Marilyn, Garavalia, Linda y Gredler, Margaret. (2003). Gender differences in selfregulated learning, task value, and achievement in developmental college students. Paper presented at the annual meeting of the American Educational Research Association, Chicago, IL.

Rowe, John. (2002). First year engineering students' approaches to study. International Journal of Electrical Engineering Education, 39(3), 201-210.

Sigal, Víctor. (2003). La cuestión de la admisión a los estudios universitarios en Argentina (Documento de Trabajo $\mathrm{N}^{\circ}$ 113). Universidad de Belgrano. Recuperado de: http://www.ub.edu.ar/investigaciones/dt nuevos/113 sigal.pdf 
Silva, Renato (2005). Deserción: ¿competitividad o gestión? Revista Lasallista de Investigación, 2(2), 64-69.

Tynjälä, Päivi; Salminenb, Risto; Sutela, Tuula; Nuutinena, Anita; Pitkänen, Seppo (2005). Factors related to study success in engineering education. European Journal of Engineering Education, 30(2), 221-231.

Valadas, Sandra Teodósio, Ribeiro Gonçalves, Fernando y Madeira Faísca, Luis. (2010). Students profiles in a portuguese higher education. Documento presentado en la reunión anual de la Society of Research in Higher Education, Wales, Reino Unido. Recuperado de http://www.srhe.ac.uk/conference2010/abstracts/0026.pdf

Vázquez, Stella Maris. (2009). Rendimiento académico y patrones de aprendizaje en estudiantes de Ingeniería. Ingeniería y Universidad, 13(1), 105-136.

Vázquez, Stella Maris y Noriega Biggio, Marianela. (2010). La competencia espacial. Evaluación en alumnos de nuevo ingreso a la universidad. Educación Matemática, 22(2), 65-91.

Vázquez, Stella Maris, García Stella Maris y Noriega Biggio, Marianela. (2011). Componentes de la competencia espacial. Exploración en ingresantes a la Facultad de Arquitectura, Diseño y Urbanismo. Revista de Orientación Educacional. Universidad de Playa Ancha, Chile, 25(47), 95-112.

Vázquez, Stella Maris, Noriega Biggio, Marianela y García, Stella Maris. (2013). Relaciones entre rendimiento académico, competencia espacial, estilos de aprendizaje y deserción. REDIE, Revista Electrónica de Investigación Educativa, 15(1), 29-44.

Vermunt, Jan. (1998). The regulation of constructive learning processes. British Journal of Educational Psychology, 68, 149-171.

Vermunt, Jan D. y Verloop, Nico. (1999). Congruence and friction between learning and teaching. Learning and Instruction, 9, 257-280.

Voyer, Daniel, Voyer, Susan y Bryden, Philip. (1995). Magnitude of sex differences in spatial abilities: A meta-analysis and consideration of critical variables. Psychological Bulletin. $117,250-270$.

Vrugt, Anneke y Oort, Frans. (2008). Metacognition, achievement goals, study strategies and academic achievement: pathways to achievement. Metacognition and Learning, 3(2), 123-146.

Washer, Peter (2007). Revisiting key skills: a practical framework for higher education. Quality in Higher Education, 13(1), 57-67. 